\title{
PENGARUH KUALITAS LAYANAN TERHADAP KEPUASAN PELANGGAN DIBANK SYARIAH MANDIRI SIDOARJO
}

Shinta Deffi

Email: eddograntino@gmail.com

Fakultas Bisnis dan Ekonomika, Universitas, Surabaya, Indonesia

\begin{abstract}
The quality of service in a banking service company is very important from the consumer's point of view. The purpose of this study was to determine and explain the effect of service quality on customer satisfaction at Bank Syariah Mandiri Juanda in Sidoarjo. This quantitative descriptive study uses a survey method by distributing questionnaires to respondents. Some of the tests carried out were the validity and reliability of the questionnaire, the classical assumption test, and the statistical test (simple linear regression). The results of the regression analysis show that service quality has a significant effect on customer satisfaction.
\end{abstract}

Keyword: Bank Syariah Mandiri, Quality, Services, Sidoarjo

\section{PENDAHULUAN}

Dalam industri perbankan, kualitas dan kepuasan pelanggan berkaitan erat. Kualitas memberikan suatu dorongan kepada pelanggan (nasabah) untuk menjalin ikatan yang kuat dengan perusahaan. Orientasi pada kepuasan nasabah diperlukan karena, nasabah merasa puas terhadap layanan bank sehingga bank dapat mempertahankan nasabahnya agar tidak beralih ke bank lainnya dan nasabah menceritakan mengenai pelayanan bank yang memuaskan kepada orang lain yang pada akhirnya merupakan sarana promosi yang efektif (Sunardi, 2003: 69).

Kualitas pelayanan dalam perusahaan jasa adalah hal yang sangat penting dari sudut pandang konsumen. Konsumen tidak hanya menilai dari hasil jasa, tetapi juga dari proses penyampaian jasa tersebut (Gronross, 2000). Kotler (1997) berpendapat bahwa perusahaan-perusahaan yang bergerak di bidang perbankan merupakan bisnis jasa yang berdasarkan atas azas kepercayaan sehingga masalah kualitas pelayanan menjadi faktor yang sangat menentukan dalam keberhasilan usaha.

Responsiviness (daya tanggap) menunjukkan hubungan signifikan dalam memprediksi kepuasan pelanggan terhadap keseluruhan layanan perbankan. Dalam studi Mosahab dan Ramayah (2010), menemukan bahwa semua aspek harapan pelanggan ternyara lebih tinggi dari persepsi mereka tentang operasi bank. Kepuasan pelanggan berperan sebagai mediator terhadap pengaruh kualitas jasa pelayanan dan loyalitas nasabah.

Dalam Standar Nasional Indonesia yang disusun Dewan Standarisasi Nasional (Rita, 2001) mendefinisi mutu atau kualitas adalah gambaran dan karakteristik menyeluruh dari barang atau jasa yang menunjukkan kemampuannya dalam memuaskan kebutuhan yang ditentukan atau tersirat.

Pada konsep kepuasan pelanggan, setiap individu mempunyai peranan yang sangat penting terhadap kepuasan yang dibentuk. Kotler dan Armstrong (1994) dalam Fandy (1999) mengemukakan bahwa kepuasan pelanggan adalah tingkat perasaan seseorang setelah membandingkan kinerja (hasil) yang ia rasakan dibanding dengan harapannya. Tingkat kepuasan merupakan fungsi dari perbedaan kinerja yang dirasakan dengan harapan yang diinginkan.

Kepuasan pelanggan keseluruhan menurut Spreng (1996) dalam Candra (2001) didefinisikan sebagai pernyataan afektif tentang reaksi emosional terhadap pengalaman atas produk atau jasa, yang dipengaruhi oleh kepuasan konsumen terhadap produk tersebut (atribut kepuasan) dan 
dengan informasi yang digunakan untuk memilih produk (informasi kepuasan).

Tujuan penelitian ini adalah untuk mengetahui dan menjelaskan pengaruh kualitas layanan terhadap kepuasan pelanggan Bank Syariah Mandiri Juanda di Sidoarjo.

\section{METODE PENELITIAN}

Penelitian deskriptif kuantitatif ini menggunakan metode survey dengan menyebarkan kuesioner kepada responden (Husein, 2011; Sugiyono, 2011). Teknik pengambilan sampel yang digunakan dalam penelitian ini adalah non-probability sampling terhadap nasabah Bank Mandiri Syariah Komplek Ruko Juanda, Waru. Skala pengukuran dalam penelitian ini menggunakan numerical scale dengan menggunakan lima poin skala likert (Zikmund, 2011). Beberapa uji yang dilakukan adalah uji validitas dan reliabilitas kuesioner, uji asumsi klsik, dan uji statistik (regresi linier sederhana).

\section{HASIL DAN PEMBAHASAN}

Uji validitas dan realibilitas atas kuesioner yang dilakukan telah menghasilkan kuesioner yang siap untuk disebarkan. Selanjutnya, berdasarkan 100 jawaban kuesioner yang masuk, responden laki-laki mencapai 57\%. Pekerjaan rresponden terdistribusi sebagai karyawan swasta (25\%), wiraswasta (11\%), PNS (28\%), BUMN (17\%), sisanya 4\%. Pendidikan responden didominasi S1 (47\%) dan SMA/SMK (32\%). Berdasarkan jumlah tabungan, didominasi oleh jumlah tabungan Rp500.000-Rp. 1.500.000 (45\%) dan > Rp. 1.500 .000 (47\%). Berdasarkan lama menjadi nasabah, durasi 1 - 2 tahun mencapai $63 \%$, sedangkan > 2 tahun mencapai $31 \%$.

Uji asumsi klasik, pertama uji normalitas Kolmogorov-Smirnov yang menunjukkan data dalam penelitian ini tidak berdistribusi normal. Kedua, uji multikolinearitas yang dihasilkan bahwa semua data dalam penelitian ini bebas dari masalah multikolinearitas. Uji ketiga adalah uji heteroskedastisitas yang menunjukkan bahwa semua data dalam penelitian ini bebas dari masalah heterokedastisitas.

Selanjutnya dilakukan uji statistik dengan analisis regresi sederhana (Tabel 1). Persamaan garis regresi yang dihasilkan adalah:

$$
\begin{aligned}
& Y=a+b X+e \\
& Y=20.677+0,754 X+e
\end{aligned}
$$

Artinya, nilai variableKepuasan Pelanggan (Y) dapat dilihat dari nilai konstanta sebesar 20,667 dengan catatan jika variiabel independen Kualitas Layanan (X) tidak mempengaruhi variabel 
dependen kepuasan pelanggan (Y). Nilai koefisien (X) sebesar 0,754 dapat diartikan apabila kualitas layanan meningkat 1 satuan maka kepuasan pelanggan akan naik sebesar 0,754 satuan. Sementara itu, koefisien determinasi yang diperoleh ditampilkan di Tabel 2.

Tabel 1 Hasil Analisis Regresi Sederhana

Coefficients $^{\mathrm{a}}$

\begin{tabular}{|c|c|c|c|c|c|c|c|}
\hline \multirow[t]{2}{*}{ Model } & \multicolumn{2}{|c|}{$\begin{array}{c}\text { Unstandardized } \\
\text { Coefficients }\end{array}$} & \multirow{2}{*}{$\begin{array}{c}\begin{array}{c}\text { Standardized } \\
\text { Coefficients }\end{array} \\
\text { Beta }\end{array}$} & \multirow[t]{2}{*}{$\mathrm{t}$} & \multirow[t]{2}{*}{ Sig. } & \multicolumn{2}{|c|}{ Collinearity Statistics } \\
\hline & $\mathrm{B}$ & Std. Error & & & & Tolerance & VIF \\
\hline (Constant) & 20.677 & 4.582 & & 4.512 & .000 & & \\
\hline $\begin{array}{l}\text { KUALITAS } \\
\text { LAYANAN }\end{array}$ & .754 & .062 & .775 & 12.151 & .000 & 1.000 & 1.000 \\
\hline
\end{tabular}

Tabel 2 Hasil Uji Koefisien Determinasi $\left(\mathbf{R}^{2}\right)$

Model Summary ${ }^{b}$

\begin{tabular}{llrcrr}
\multicolumn{6}{c}{ Model Summary $^{\mathbf{b}}$} \\
Model & $\mathrm{R}$ & $\mathrm{R}$ Square & $\begin{array}{c}\text { Adjusted R } \\
\text { Square }\end{array}$ & $\begin{array}{c}\text { Std. Error of the } \\
\text { Estimate }\end{array}$ & Durbin-Watson \\
\hline 1 & $.775^{\mathrm{a}}$ & .601 & .597 & 6.83590 & 2.105 \\
\hline
\end{tabular}

Sumber: Data primer, 2020

b. Dependent Variable: KEPUASAN PELANGGAN

Berdasarkan Tabel 2 didapatkan nilai R square (R2) sebesar 0,597,sehingga dapat diketahui bahwa variable Kualitas Layanan (X) mampu menjelaskan 59,7\% terhadap variable kepuasan pelanggan (Y). Sedangkan sisanya sebesar 40,3\% dijelaskan oleh variable lain di luar penelitianini.

Variabel Kualitas Layanan memiliki pengaruh positif dan signifikan terhadap Kepuasan Pelanggan Bank Syariah Mandiri di Juanda Sidoarjo. Hal ini dapat dibuktikan dengan nilai t hitung lebih besar dari t tabel $(12.151>1,984)$ dengan nilai signifikansi sebesar $0,000(0,000<0,05)$. Koefisien determinasi $\left(\mathrm{R}^{\wedge} 2\right)$ yang diperoleh nilai 59,7\% menunjukkan variabel kualitas layanan berpengaruh positif dan mempengaruhi $59,7 \%$ perubahan terhadap tingkat kepuasan pelanggan Bank Syariah Mandiri di Juanda Sidoarjo.

Dengan kata lain, jika besar kualitas layanan yang dirasakan oleh nasabah dalam merasakan layanan yang baik di bank itu maka semakin besar pula keputusan nasabah maupun calon nasabah untuk memberikan nilai kepuasan yang tinggi akan terus meningkat.

Hasil penelitian ini sejalan dan diperkuat dengan penelitian Sanistasya (2015) bahwa Kualitas pelayanan memiliki pengaruh yang signifikan terhadap kepuasan nasabah/pelanggan.

\section{KESIMPULAN}

Hasil analisis regresi menunjukkan bahwa kualitas layanan berpegaruh signifikan terhadap kepuasan pelanggan Bank Syariah Mandiri di Juanda Sidoarjo. Semakin baik kualitas layanan yang diberikan kepada pelanggan, maka kepuasan akan meningkat secara signifikan. Secara umum 
kualitas layanan Bank Syariah Mandiri di Juanda Sidoarjo dinilai baik oleh pelanggan, sehingga hal ini dapat menunjang loyalitas.

\section{DAFTAR PUSTAKA}

Gronroos, C., 2000, Service Management and Marketing: A Customer Relationship Management Approach (2nd ed). Chichester: John Wiley and Sons, Ltd.

Husein, Umar, 2011, Metode Penelitian Untuk Skripsi dan Tesis Bisnis, Edisi 11. Jakarta: PT Raja Grafindo Persada

Mosahab, Mahamad, dan Ramayah, 2010. Service Quality, Customer Satisfaction and Loyalty: A Test of Mediation, The Jurnal Business Research, Volume 3, Number 4, October 2010.

Kotler, Philip and Garry Armstrong, 1994, Principle of Marketing, 7th Ed, Prentice Hall International, Inc, New Jersey

Kotler, Philip, 1997, Manajemen Pemasaran. Edisi Bahasa Indonesia jilid satu. Jakarta: Prentice Hall.

Sanistasya, Poppy Alvianolita, 2015, Pengaruh Kualitas Pelayanan Terhadap Kepuasan Nasabah Dan Loyalitas Nasabah Tabungan Britama Pada PT Bank Rakyat Indonesia (Persero) Tbk Cabang Samarinda. E-Jurnal Ilmu Administrasi Bisnis, Universitas Diponegoro, Semarang. ISSN 2355-5408.

Spreng, E., 1996, Information Processing. Asia Pacific Association for Consumer and Business Studies.

Sugiyono. 2011. Metode Penelitian Pendidikan (Pendekatan. Kuantitatif, Kualitatif, dan R\&D). Bandung: Alfabeta.

Zikmud, William G., 2011, Business Research Methods (eighth edition). South Western, USA: Cengage Learning. 